\title{
PERGAMON
}

www.elsevier.com/locate/watres

\section{MULTICOMPONENT BIOSORPTION IN FIXED BEDS}

\author{
DAVID KRATOCHVIL and BOHUMIL VOLESKY* \\ Department of Chemical Engineering, McGill University, 3610 University Street, Montreal, Canada \\ $\mathrm{H} 3 \mathrm{~A} 2 \mathrm{~B} 2$
}

(First received 1 June 1999; accepted in revised form 1 November 1999)

\begin{abstract}
The biosorption of $\mathrm{Cu}, \mathrm{Zn}, \mathrm{Cd}$ and $\mathrm{Fe}$ from multicomponent mixtures was studied in a flowthrough column packed with Sargassum algal biosorbent in the Ca-form. The effects of competitive ion exchange such as the elution order of toxic metals from the column, and the concentration overshoots in column effluent were investigated both experimentally and by means of an ion exchange equilibrium column model (ECM). The ECM predicted, and the experiments confirmed, that from the feed containing $\mathrm{Cu}^{2+}, \mathrm{Zn}^{2+}$ and $\mathrm{Cd}^{2+}$, zinc broke through the column first, followed by cadmium and copper. When the binary mixtures containing $30 \mathrm{mg} / 1$ of $\mathrm{Cu}^{2+}$ and $4 \mathrm{mg} / 1$ of either $\mathrm{Cd}^{2+}$ or $\mathrm{Zn}^{2+}$ were passed through the column, the concentrations of $\mathrm{Zn}$ and $\mathrm{Cd}$ ions in the column effluent overshot the $4 \mathrm{mg} / \mathrm{l}$ feed concentration. The time interval between the overshoot of $\mathrm{Zn}$ and the breakthrough point of $\mathrm{Cu}$ was significantly longer than that between the overshoot of $\mathrm{Cd}$ and the breakthrough point of $\mathrm{Cu}$. However, $\mathrm{Zn}$ did not overshoot when the feed contained $50 \mathrm{mg} / \mathrm{l}$ of Cd and $4 \mathrm{mg} / \mathrm{l}$ of $\mathrm{Zn}$. The ECM successfully predicted both the occurrence and the magnitude of the overshoots. The service time of a column treating multimetal mixtures was successfully predicted by combining the ECM with a mass transfer column model (MTCM). (C) 2000 Elsevier Science Ltd. All rights reserved
\end{abstract}

Key words - biosorption, Sargassum, muticomponent sorption, column

\section{NOMENCLATURE}

$C_{\mathrm{M}}$

$C_{\mathrm{M}}=x_{\mathrm{M}}$

$C_{\mathrm{ML}}$

$C_{\mathrm{Mf}}$

$C_{\mathrm{M} 0}$

$C_{\mathrm{CNT}}$

$C_{\mathrm{CNT} 0}$

$C_{\mathrm{t}}$

$C_{0}$

$D_{\mathrm{Z}}$

$F$
$K_{\mathrm{fM}}$

$K_{\mathrm{fM}}$

$K_{i j}$

$l$

$L_{0}$

$M_{\mathrm{WM}}$

$M_{\mathrm{WCNT}}$

$q_{\mathrm{MS}}$

$q_{\mathrm{M}}=y_{\mathrm{M}}$ [meq/l] liquid phase [meq/l] a column phase a column g]

volumetric flowrate $\left[\mathrm{m}^{3} / \mathrm{h}\right]$ $\left[\mathrm{min}^{-1}\right]$ equation (2)[-] length of the column [cm] equilibrium concentration of species $M[\mathrm{meq} / \mathrm{l}]$ equivalent fraction of species $M$ in liquid phase concentration of species $M$ in liquid phase

equilibrium final concentration of species $M$ in

equivalent fraction of species $M$ in the feed to

equivalent fraction of counterion in liquid

equivalent fraction of counterion in the feed to concentration of binding sites in biomass [meq/

normality of the column feed [meq/l]

axial dispersion coefficient $\left[\mathrm{cm}^{2} / \mathrm{s}\right]$

overall mass transfer coefficient of species $M$

equilibrium binding constant defined by $\rho_{\mathrm{b}}$

vertical distance from the top of a column

molecular weight of the sorbing metal

molecular weight of the counterion

uptake of species $M$ by the biosorbent [meq/g]

equivalent fraction of species $M$ in solid phase

*Author to whom all correspondence should be addressed. Tel.: + 1-514-398-4276; fax: + 1-514-398-6678; e-mail: boya@chemeng.lan.mcgill.ca
$Q \quad$ concentration of binding sites in the biosorbent [meq/g]

$T \quad$ throughput parameter defined by equation (3) [-]

$T_{\text {UD }} \quad$ value of $T$ corresponding to an abrupt transition between a downstream plateau $D$ and an upstream plateau $U[-]$

$T_{\mathrm{UD}}^{\prime}, T_{\mathrm{UD}}^{\prime \prime}$ values of $T$ corresponding to the beginning and the end of a gradual transition between plateaus $D$ and $U[-]$

$v$ intersticial velocity in packed-bed column $[\mathrm{cm} /$ min]

$V_{\mathrm{c}} \quad$ volume of the packed-bed in a column[-]

$x_{\mathrm{MP}} \quad$ equivalent fraction of species $M$ in liquid at the plateau $P$ in column

$y_{\mathrm{MP}} \quad$ equivalent fraction of species $M$ in solid at the plateau $P$ in column

$\epsilon \quad$ column void fraction

$v \quad$ stoichiometric coefficient of the exchange reaction, equation (12)

packing density $[\mathrm{g} / \mathrm{l}]$

$\begin{array}{ll}\rho_{\mathrm{b}} & \text { time }[\mathrm{min}]\end{array}$

Dimensionless groups

$D_{\mathrm{gM}}=\frac{\rho_{\mathrm{b}} Q}{C_{0} \varepsilon} \quad$ solute distribution parameter

$P \mathrm{e}_{\mathrm{c}}=\frac{L_{0} v}{D_{\mathrm{Z}}} \quad$ column Peclet number

$S h_{\mathrm{M}}=\frac{K_{\mathrm{jM}} L_{0}}{v}$ modified Sherwood number

\section{INTRODUCTION}

Biosorption is a water purification process whereby 
toxic heavy metals are removed from aqueous solutions by sorption onto inexpensive biomaterials. The primary incentives for the development of biosorption into a full-scale industrial process are the low cost of biosorbents and the high efficiency of detoxification of wastewater containing low concentrations of heavy metals.

Despite numerous indications of ion exchange as the principal mechanism of biosorption by dead biomass (Crist et al., 1994; Fourest and Roux, 1994; Schiewer and Volesky, 1996), most studies of biosorption continue to analyze experimental data obtained from both biosorption column (JanssonCharrier et al., 1996; Muraleedharan et al., 1994) and batch systems (Al-Asheh and Duvniak, 1995; Churchill et al., 1995; Tsezos et al., 1995) by means of models originally developed for sorption on granular activated carbon (GAC). Although the models of sorption on GAC may fit experimental data for a specific system under examination, these models cannot predict such fundamental effects as those of $\mathrm{pH}$, solution normality and the ionic form of the biosorbent on sorption and desorption of heavy metals. In fact, the models for GAC fail to recognize that biosorbents may operate on different ionic cycles, which are determined by the types of acids and/or bases used for pretreating biomass, for desorbing heavy metals, and for regenerating the biosorbents. By using the theory of ion exchange to select ionic cycles for seaweed biomass, Kratochvil et al. (1997) optimized the performance of a flowthrough column removing $\mathrm{Cu}$ from water.

In columns treating multi-metal mixtures, heavy metals ions compete for a limited number of binding sites in the biomass. Depending on the composition of wastewater and the form of biomass, this competitive ion exchange may severely reduce the efficiency of the metal removal process. Let us consider an industrial effluent containing two toxic species, $\mathrm{A}$ and $\mathrm{B}$. While the concentration of $\mathrm{A}$ in the wastewater is relatively high, species B is present at a level considered acceptable for industrial discharges. Furthermore, species A has a higher affinity towards the biosorbent than species $\mathrm{B}$ and hence is efficiently removed by the column. However, as a result of competitive ion exchange, species B overshoots the acceptable limit in the column effluent well before the breakthrough point of $\mathrm{A}$, thereby reducing the service time of the column considerably. The overshoots for a variety of metals and biomasses have been reported in the literature (Costa et al., 1996; Kratochvil and Volesky, 1997; Trujillo et al., 1991) but hardly ever explained.

In order to facilitate the evaluation of a performance of ion exchange columns treating multi-ion mixtures, Klein et al. (1967) and Helfferich (1967) developed the equilibrium column model (ECM). Based solely on the values of equilibrium constants, the ECM can predict the elution order of the components, the lowest biosorbent usage rate, the occurrence of overshoots, and the maximum overshoot concentrations.

The objectives of this work were to demonstrate the use of the ECM for (1) predicting the occurrence and magnitude of overshoots of toxic heavy metals sorbing onto Sargassum algal biomass in flow-through columns, and (2) reducing the amount of information needed for dynamic simulations of multicomponent biosorption in columns using the mass transfer column model (MTCM). By addressing these objectives, a methodology is developed which can assist researchers and engineers in evaluating the efficiency of the biosorption process using columns with respect to wastewater composition.

\section{THEORETICAL APPROACH}

It has been demonstrated that the binding of metals by algal biomass from aqueous solutions can be described by the ion exchange reaction,

$$
\begin{aligned}
& M_{i}^{2+}+\left(M_{j}-\text { biomass }\right) \\
& \leftrightarrow M_{j}^{2+}+\left(M_{i}-\text { biomass }\right)
\end{aligned}
$$

where $M_{i}$ and $M_{j}$ stand for divalent heavy metal cations sorbed and released from the biomass, respectively (Kratochvil and Volesky, 1997). Assuming that activity coefficients of the species $M_{i}$ and $M_{j}$ in both phases are equal to one, the equilibrium binding constant for the reaction (1) is defined as

$$
K_{i j}=\frac{1}{K_{j i}}=\frac{q_{i} C_{j}}{q_{j} C_{i}}=\frac{y_{i} x_{j}}{y_{j} x_{i}}
$$

where $y_{i}, y_{j}$ and $x_{i}, x_{j}$ represent the equivalent fractions of the species $M_{i}$ and $M_{j}$ in the biosorbent, and in the liquid, respectively. Clearly, for mixtures containing more than two metal species, an equilibrium constant $K_{i j}$ can be defined for every pair of components $i, j$ in the mixture. However, a knowledge of only $N-1$ equilibrium constants $K_{i j}$ is sufficient for a complete description of the biosorption equilibrium in $N$-component mixtures, since any additional $K_{i j}$ may be calculated simply by combining the already known constants.

\section{ECM-basic concepts and symbol conventions}

The defining characteristics of the ECM are assumptions of negligible mass transfer resistance, constant feed composition, uniform biosorbent/ resin presaturation, homogeneity of the bed, no precipitation in the bed, and no axial dispersion in the direction of the flow.

The ECM describes an ion exchange column as being divided into zones of unique constant compositions, called plateaus, separated from each other by zones of varying composition, called transitions. The plateaus and transitions are numbered starting from the feed end of the column; each plateau is 
assigned a number, while each transition is designated by a pair of numbers corresponding to the numbers of the adjacent plateaus. The respective compositions of the plateaus and transitions, as well as their appearance or disappearance, follow two basic rules derived by Klein (Klein et al., 1967) and referred to as the "alphabet" and the "slope" rules. Furthermore, the ECM identifies each transition as being of either a constant-pattern or a proportionate-pattern type. A symbol convention assigns the letters of the alphabet to the components of the mixture in the order of decreasing affinity of the components towards the resin/biosorbent. Thus, A always represents the most strongly bound component.

The number of plateaus which develop in a column is usually equal to the number of components present in the column feed (Klein et al., 1967). Special situations, where the number of plateaus is lower than the number of components, are described elsewhere (Helfferich, 1967; Klein et al., 1967; Tondeur and Klein, 1967).

The alphabet rule states that the concentration of A can go to zero only in the 1,2 transition; component $\mathrm{B}$ in the 1,2 or 2,3 transitions; component $\mathrm{C}$ in the 2,3 or 3,4 transitions; etc. Two components may vanish in the same transition, however never at the same end of a transition.

A positive slope is assigned to components whose concentrations increase in the direction of the flow within a given transition. Similarly, a negative slope is assigned to components whose concentrations decrease in the direction of the flow within a given transition. The slope rule states that $\mathrm{A}$ has a positive slope in the 1,2 transition; A, and B have positive slopes in the 2,3 transition; $\mathrm{A}, \mathrm{B}$, and $\mathrm{C}$ have positive slopes in the 3,4 transition; etc. The slopes of all of the other components are negative.

As first mathematically proven by deVault (1943), different parts of a transition may travel down the column at different speeds. If the points downstream move faster than the points upstream, a transition is being extended and the distance between the two plateaus adjacent to the transition increases. Such transitions are called proportionatepattern or gradual. In contrast, if the points upstream move faster than the points downstream, the transition shrinks. In reality, the fast moving points can never overtake the slow moving points. Therefore, in graphs, such transitions are represented by a point at which the concentration profiles of all of the species form a step connecting levels of the species attained in the two adjacent plateaus (Klein et al., 1967). Such transitions are called constant-pattern or abrupt. In theory, the fast moving points in an abrupt transition take over the slow moving ones, hence yielding positive slopes for components present in the feed but absent from the presaturation liquid. Consequently, where the slopes of these components are negative, the transitions can be identified as gradual. Once a transition has been identified as either abrupt or gradual for one of the components in the mixture, the transition is abrupt or gradual for all the remaining components.

Mathematically, the ECM represents a combination of equilibrium relationships (2), electroneutrality equations (7(a) and(b)), and equations (4), (5) and (8), which were derived from the theory of chromatography (deVault, 1943; Vermeulen et al., 1973). The chromatographic equations (4), (5) and (8) relate the changes in the composition in the solid and in the liquid to the dimensionless time $T$ called throughput defined as:

$$
T=\frac{C_{0} F \tau}{\rho_{\mathrm{b}} Q V_{\mathrm{c}}}
$$

where $C_{0}$ is normality of the column feed, $F$ is volumetric flowrate, $\tau$ is time, $\rho_{\mathrm{b}}$ is packing density, $Q$ is concentration of binding sites in the biosorbent [meq $/ \mathrm{g}$ ], and $V_{\mathrm{c}}$ is volume of the column packedbed. All other symbols are listed separately.

The concentration history in a column effluent, represented by a series of points $\left[x_{i}, T\right]$ $(i=1, \ldots N)$, is a mirror image of the concentration profiles developed in the column. Hence plotting $x_{i}$ vs $1 / T$ yields a picture of plateaus and transitions in the sequence in which they developed in the column.

\section{ECM equations for transitions}

Equations (4) and (5) were derived for gradual transitions in multicomponent systems:

$$
\begin{gathered}
\frac{d x_{i}}{d k_{k}}=\frac{x_{i} y_{i}}{x_{k} y_{k}} \frac{T x_{k}-y_{k}}{T x_{i}-y_{i}} \quad i=1, \ldots, N-1 \\
\sum_{i=1}^{N} \frac{x_{i} y_{i}}{T x_{i}-y_{i}}=0 \quad\left(x_{i} \neq 0 ; y_{i} \neq 0\right)
\end{gathered}
$$

For the $N$-component system, equation (5) has $N$-1 positive roots $T_{1}, T_{2}, \ldots T_{N-1}$ such that

$$
\frac{y_{\mathrm{A}}}{x_{\mathrm{A}}}>T_{1}>\frac{y_{\mathrm{B}}}{x_{\mathrm{B}}}>T_{2}>\frac{y_{\mathrm{C}}}{x_{\mathrm{C}}}>\ldots
$$

In this series $T_{1}$ applies to the position of the first plateau, $T_{2}$ to the second plateau, and so on. Series (6) is useful as it provides limits between which $T$ can change in a given transition. In order to obtain the part of the overall concentration profiles in an effluent, corresponding to a gradual transition represented by equations (2), (4), (5) and (7(a) and (b)), these were solved according to the method outlined by Klein et al. (1967).

$$
1-\sum_{i=1}^{N} y_{i}=0
$$




$$
1-\sum_{i=1}^{N} x_{i}=0
$$

An abrupt transition between an upstream plateau $\mathrm{U}$ and a downstream plateau $\mathrm{D}$ in a multicomponent system is characterized by the equation (8):

$$
T_{\mathrm{UD}}=\frac{y_{i \mathrm{D}}-y_{i \mathrm{U}}}{x_{i \mathrm{D}}-x_{i \mathrm{U}}} \quad i=1, \ldots, N-1
$$

The subscripts $\mathrm{U}$ and $\mathrm{D}$ for $x$ and $y$ represent the numbers corresponding to the upstream and downstream transitions, respectively. For a known composition of the upstream plateau, the unknowns in equation (8) are $x_{i \mathrm{D}}, y_{i \mathrm{D}}$ and $T_{\mathrm{UD}}$ so that, for an $\mathrm{N}$-component system, the total number of unknowns is $2 \mathrm{~N}+1$. The unknowns are determined by solving simultaneously equations (2), (5), (7(a) and (b)) and (8). The dimensionless concentrations $x_{i}, y_{i}$, in equations (5), (7) and (8) correspond to $x_{i \mathrm{D}}$, and $y_{i \mathrm{D}}$. The equations were solved by the method introduced by Klein et al. (1967).

\section{Calculation of concentration histories in column efflu-} ent

Using the ECM, complete concentration profiles of individual components in the column effluent are determined in two steps. In the first step, a qualitative overall concentration pattern is obtained by applying the alphabet and the slope rules to the given system. The overall number of plateaus and transitions is determined, the likelihood of occurrence of individual components in individual transitions is evaluated. Furthermore, by taking into account the composition of the feed and the ionic form of the sorbent, most of the transitions can already be identified as either abrupt or gradual. In the second step, the precise locations and compositions of the plateaus and transitions are calculated by applying appropriate sets of equations to the transitions. The calculation always starts from plateau 1 (closest to the feed end of the column) at which point the sorbent is in equilibrium with the feed, and then proceeds to the plateaus and transitions downstream.

Brief outline of the mass transfer column model (MTCM)

Two relatively recent studies of biosorption in fixed-bed columns employed models originally developed for sorption of a single solute (Volesky and Prasetyo, 1994) and for a multicomponent mixture (Trujillo et al., 1991) on activated carbon. In the case of heavy metal biosorption by algal biomass, however, an ion exchange model rather than a model of activated carbon sorption should be used since a considerable amount of ions is being released from the biosorbent in exchange for the heavy metal. The approaches used for modeling ion exchange in fixed beds by Hiester and Vermeulen
(1952) for single solute, and by Helfferich (1967) and by Klein et al. (1967) for multicomponent mixtures, are restricted to systems with constant separation factors and/or to infinitely long fixed beds for which the assumption of a local equilibrium is valid. The most universal approach seems to be the one adopted by Tan and Spinner (1994) who numerically solved a mixed system of partial differential, ordinary differential, and algebraic equations describing the dynamics of multicomponent ion exchange in a fixed-bed. In this work, the model of Tan and Spinner (1994) has been adopted as outlined earlier (Kratochvil et al., 1997) which is restricted to binary systems, i.e. single solute ion exchange, which allows us to test the approach for the case of biosorption while reducing the number of equations to a minimum. A term has also been added to the differential molar balance equation, in order to account for axial dispersion of the fluid in the packed-bed. Assuming isothermal conditions and constant physical properties for the feed solution, the differential molar balance for a sorbing species $M$ is

$$
\frac{\partial C_{\mathrm{M}}}{\partial z}-\frac{1}{P e_{c}} \frac{\partial^{2} C_{\mathrm{M}}}{\partial z^{2}}+\frac{\partial C_{\mathrm{M}}}{\partial t}+D_{\mathrm{gM}} \frac{\partial q_{\mathrm{M}}}{\partial t}=0
$$

The sorption rate equation can be written as

$$
\frac{\partial q_{\mathrm{M}}}{\partial t}=S h_{\mathrm{M}}\left(q_{\mathrm{M}}^{*}-q_{\mathrm{M}}\right)
$$

assuming a linear driving force for the sorption process and combined film and intraparticle mass transfer resistance. The basic equilibrium relationship for a metal species (Kratochvil et al., 1997) can be written schematically for a general counterion, i.e. either proton or metal, as

$$
q_{\mathrm{M}}^{*}=f\left(C_{\mathrm{M}}, C_{\mathrm{CNT}}\right)
$$

and the electroneutrality equation for binary systems is

$$
\frac{C_{\mathrm{M} 0}-C_{\mathrm{M}}}{M_{\mathrm{WM}}}=v \frac{C_{\mathrm{CNT} 0}-C_{\mathrm{CNT}}}{M_{\mathrm{WCNT}}}
$$

To obtain equations (9)-(12), the original set of equations was transcribed with dimensionless variables using the following transformations of the variables:

$$
C_{\mathrm{M}}=\frac{C_{\mathrm{ML}}}{C_{0}} \quad q_{\mathrm{M}}=\frac{q_{\mathrm{MS}}}{Q} \quad t=\frac{\tau v}{L_{0}} \quad z=\frac{l}{L_{0}}
$$

and yielding the following dimensionless groups:

$$
D_{\mathrm{gM}}=\frac{\rho_{\mathrm{b}} Q}{C_{0} \epsilon} \quad S h_{\mathrm{M}}=\frac{K_{\mathrm{jM}} L_{0}}{v} \quad P e_{\mathrm{c}}=\frac{L_{0} v}{D_{\mathrm{z}}}
$$

The initial and boundary conditions pertaining to the situations under question are specified as follows: 


$$
\begin{gathered}
t=0 \quad l=\left(0, L_{0}\right) \quad C_{\mathrm{M}}=0 \\
t>0 \quad l=0 \quad C_{\mathrm{M}}=C_{\mathrm{M} 0}+\frac{1}{P e_{\mathrm{c}}} \frac{\partial C_{\mathrm{M}}}{\partial z} \\
t>0 \quad l=L_{0} \quad \frac{\partial C_{\mathrm{M}}}{\partial z}=0
\end{gathered}
$$

The system of equations (9)-(12) was solved numerically by using Galerkin finite element method (Fletcher, 1984), combined with the implicit Euler method for time integration.

\section{MATERIALS AND METHODS}

\section{Biosorbent}

Sargassum seaweed biomass was collected dry on a beach of Florida Gulf Coast (in August). In the laboratory, the biomass was first protonated by soaking it for $3 \mathrm{~h}$ with $0.2 \mathrm{M} \mathrm{H}_{2} \mathrm{SO}_{4}$, subsequently it was rinsed with distilled water. Next, the conversion of the protonated biomass to Ca-biomass was carried out in a subsequent 3 - $\mathrm{h}$ wash $(10 \mathrm{~g} / \mathrm{l})$ with a $1.2 \mathrm{~g} / 1$ solution of $\mathrm{Ca}(\mathrm{OH})_{2}$. The $\mathrm{pH}$ of the spent wash solution was 11.5. Finally, the Ca-biomass was dried in the oven overnight at $50^{\circ} \mathrm{C}$.

\section{Column experiments}

Dry Ca-biomass was packed into a column yielding a biosorbent bed $40 \mathrm{~cm}$ high and $2.5 \mathrm{~cm}$ in diameter with an approximate packing density of $200 \mathrm{~g} / 1$. The column was then slowly flooded with water from the bottom. Synthetic metal solutions of $\mathrm{FeSO}_{4}, \mathrm{CuSO}_{4}, \mathrm{ZnSO}_{4}$, and $\mathrm{CdSO}_{4}$ were prepared in distilled water and subsequently fed into the column from a $40 \mathrm{~L}$ storage tank at a flowrate of $3 \mathrm{~cm}$ / $\min \left(0.75 \mathrm{gpm} / \mathrm{ft}^{2}\right)$. The concentration of $\mathrm{Cu}$ in the $\mathrm{Cu}-\mathrm{Zn}$, and the $\mathrm{Cu}-\mathrm{Cd}$ mixtures was $30 \mathrm{mg} / \mathrm{l}(0.5 \mathrm{mmol} / \mathrm{l})$ while the concentrations of $\mathrm{Zn}$ and $\mathrm{Cd}$ in these mixtures were approximately $4 \mathrm{mg} / \mathrm{l}$. The $\mathrm{Cd}-\mathrm{Zn}$ mixture contained $50 \mathrm{mg} / 1(0.5 \mathrm{mmol} / \mathrm{l})$ of $\mathrm{Cd}$ and $4 \mathrm{mg} / \mathrm{l}$ of $\mathrm{Zn}$. Finally, the $\mathrm{Cu}-\mathrm{Fe}$ mixture contained approximately $120 \mathrm{mg} / \mathrm{l}(2 \mathrm{mmol} /$ 1) of $\mathrm{Cu}$ and $110 \mathrm{mg} / \mathrm{l}(2 \mathrm{mmol} / \mathrm{l})$ of $\mathrm{Fe}^{2+}$. The flowrate, the biomass packing density, and the height of the packing were kept constant in all experiments. The feed was introduced from the top and samples of the effluent were collected from the bottom of the column by means of a fraction collector. The metal content in the samples was determined by using an inductively coupled plasma (ICP) atomic spectrometer. The $\mathrm{pH}$ of the feed varied from $\mathrm{pH} 5$ to 5.2 depending on the composition of metal solutions and, with the exception of the feed containing $\mathrm{Fe}^{2+}$, was not adjusted. The metal solution containing $\mathrm{Fe}^{2+}$ was pumped from a $40 \mathrm{~L}$ storage tank, where it was kept at $\mathrm{pH} 2.1$, to the biosorption column via a $1.5 \mathrm{~L}$ stirred tank. The $\mathrm{pH}$ in the stirred tank was maintained at $\mathrm{pH} 4$ by adding $\mathrm{NaOH}$ while nitrogen gas was continuously bubbled through the contents of the tank to prevent $\mathrm{Fe}^{2+}$ oxidation.

\section{RESULTS AND DISCUSSION}

In the first part of this work, the overshoot phenomenon in biosorption columns packed with Sargassum biosorbent in Ca-form was examined in the following three steps. First, competitive ion exchange in ternary systems was analyzed using alphabet and slope rules (Klein et al., 1967), and the conditions necessary for overshoots to occur were formulated. Next, concentration profiles obtained from the ECM were compared to experimental elution curves for selected ternary systems. And finally, the conditions under which the overshoots of certain metals could negatively affect the feasibility of a biosorption process were defined.

\section{Analyzing overshoots in ternary systems using ECM}

Figures 1(a)-(c) show three different patterns of concentration profiles which can develop in flowthrough columns, depending on the feed composition and the ionic form of the biosorbent. The patterns were obtained by applying the alphabet and slope rules to ternary biosorption systems containing species $\mathrm{A}, \mathrm{B}$, and $\mathrm{C}$. In agreement with the

a

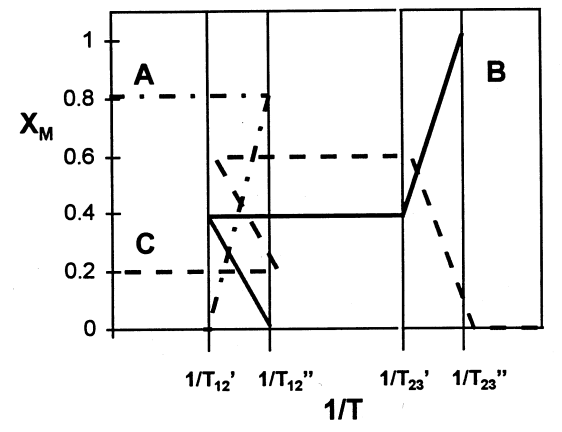

b
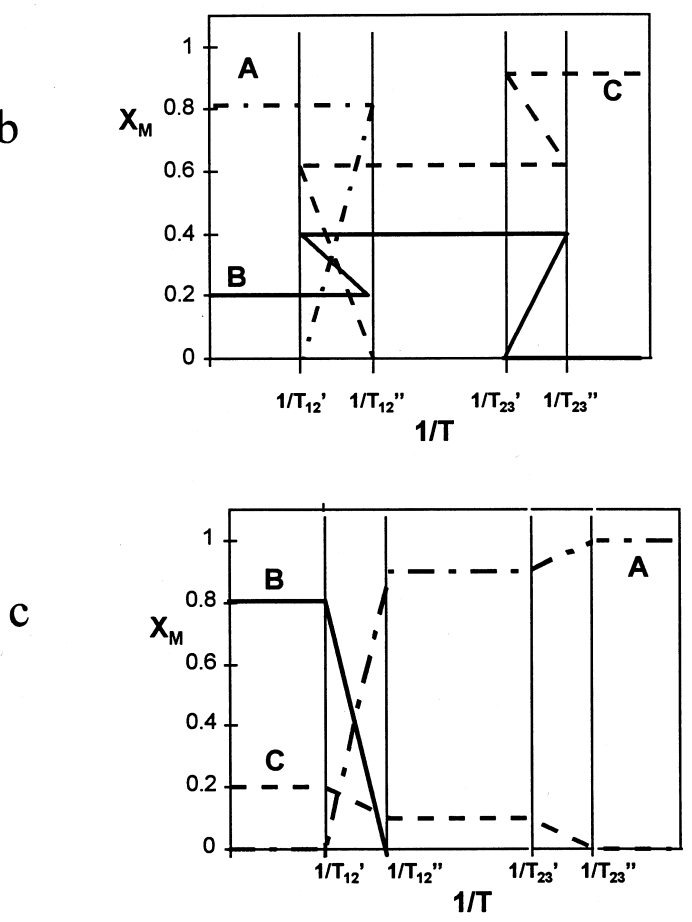

Fig. 1. Patterns of concentration profiles for ternary systems in flow-through columns: $(-\bullet) \mathrm{A}$; $(-) \mathrm{B} ;(---)$ C. (a) Feed containing $\mathrm{A}$ and $\mathrm{C}$; biosorbent in the B-form. (b) Feed containing $\mathrm{A}$ and $\mathrm{B}$; bisorbent in the C-form. (c) Feed containing $\mathrm{B}$ and $\mathrm{C}$; biosorbent in the A-form. 
symbol convention, the affinities of the species towards the biosorbent are assumed to decrease as follows $\mathrm{A}>\mathrm{B}>\mathrm{C}$. The common features of the concentration patterns in Fig. 1(a) through (c) are the three plateaus, numbered as 1,2 , and 3 , which are linked by two transitions 1,2 and 2,3. The transitions are shown with two distinct transition ends in order to visualize the slopes of the individual species in the transitions.

Figure 1(a) displays a qualitative concentration profile which develops in a column packed with biosorbent in the $\mathrm{B}$-form and receiving a feed containing species $\mathrm{A}$ and $\mathrm{C}\left(x_{\mathrm{A}}=0.8, x_{\mathrm{C}}=0.2\right)$. Since $\mathrm{B}$ is absent from the feed, and species $\mathrm{A}$ and $\mathrm{C}$ were not originally present in the biosorbent, the following must be true $x_{\mathrm{B} 1}=0$, and $x_{\mathrm{A} 3}=x_{\mathrm{C} 3}=0$. According to the alphabet and slope rules, the concentration of A must go to zero in the 1,2 transition at a positive slope. As mentioned above, the positive slope of $\mathrm{A}$ implies that transition 1,2 is abrupt. Consequently, the slopes of $\mathrm{B}$ and $\mathrm{C}$ in this transition must be negative. In order for species $\mathrm{B}$ to have a negative slope in the 1,2 transition, however, the concentration of $\mathrm{B}$ in the second plateau must be higher than in the first plateau. In further compliance with the slope rule, species $B$ and $C$ in the 2,3 transition must be assigned positive and negative slopes, respectively. Thus the transition 2,3 can be identified as gradual with the concentration of the component $\mathrm{C}$ going to zero at the transition end joining the plateau 3 . It can be seen from Fig. 1(a) that the concentration of $\mathrm{C}$ rises from zero in the 2,3 transition, reaches a maximum at the second plateau, and subsequently drops in the 1,2 transition. Hence it can be concluded that species $\mathrm{C}$ overshoots in the column effluent prior to the breakthrough of species A.

Figure 1(b) applies to a column which removes $\mathrm{A}$, and $\mathrm{B}\left(x_{\mathrm{A}}=0.8, x_{\mathrm{B}}=0.2\right)$ from the feed by sorption onto a biosorbent in the C-form. By comparing the levels of species $\mathrm{B}$ in the three plateaus displayed in Fig. 1(b), it can be seen that the level of $\mathrm{B}$ in the middle plateau is higher than in both of the neighboring plateaus. Therefore, B overshoots in the column effluent before the breakthrough of A. In contrast with Fig. 1(a), both of the transitions in Fig. 1(b) are abrupt.

Finally, Fig. 1(c) applies to the situation where the biosorbent in the column is presaturated with the most strongly bound component $\mathrm{A}$, and the wastewater contains species $\mathrm{B}$ and $\mathrm{C}\left(x_{\mathrm{B}}=0.8\right.$, $\left.x_{\mathrm{C}}=0.2\right)$. Figure $1(\mathrm{c})$ shows that both of the transitions in the profile are gradual and no species overshoots.

It is apparent from Fig. 1(a)-(c) that an overshoot occurs only if the low-affinity species from the feed is assigned a negative slope in the 1,2 transition i.e., when the 1,2 transition is abrupt. However, the transition 1,2 is abrupt only if the species with the highest affinity from the feed is more strongly bound by the biosorbent than the species with which the biosorbent had been presaturated. Consequently, a metal species may or may not overshoot in the column effluent depending on the ionic form of the biosorbent.

\section{Agreement between overshoots predicted by the ECM and experiments}

Table 1 lists the values of the equilibrium constants, as defined by equation (2), for several heavy metal ions of interest. The tabulated constants were evaluated from batch biosorption equilibrium data described elsewhere (Kratochvil and Volesky, 1997). According to the values of the constants, the metals can be arranged in the order of decreasing affinity towards the Sargassum biosorbent as follows:

$$
\mathrm{Cu}>\mathrm{Ca}>\mathrm{Cd}>\mathrm{Zn}>\mathrm{Fe} .
$$

In Fig. 2(a)-(d), the concentration profiles calculated from the ECM are compared to the experimental breakthrough curves obtained for the following mixtures $\mathrm{Cu}-\mathrm{Fe}, \mathrm{Cu}-\mathrm{Zn}, \mathrm{Cu}-\mathrm{Cd}$, and $\mathrm{Cd}-\mathrm{Zn}$, respectively, fed into columns packed with Ca-biosorbent. Figure 2(a)-(c) show that for feeds containing $\mathrm{Cu}$, all three heavy metals, i.e. $\mathrm{Fe}, \mathrm{Zn}$, and $\mathrm{Cd}$, overshot in the column effluent. However, Fig. 2(d) reveals that $\mathrm{Zn}$ did not overshoot when it was fed into the column in the mixture with $\mathrm{Cd}$. The results may be explained as follows.

According to the values of the equilibrium constants listed in Table 1, only $\mathrm{Cu}$ has a higher affinity towards Sargassum than Ca. Consequently, according to the general discussion in the preceding paragraphs, the mixtures $\mathrm{Cu}-\mathrm{Fe}, \mathrm{Cu}-\mathrm{Zn}$, and $\mathrm{Cu}-$ $\mathrm{Cd}$ can all be classified as mixtures of $\mathrm{A}-\mathrm{C}$ sorbing onto B-resin, and hence the breakthroughs produced by these mixtures on Ca-biomass must be compatible with the pattern plotted in Fig. 1(a). The overshoots of Fe, Zn, and Cd in Fig. 2(a)-(c), then correspond to the overshoot of $\mathrm{C}$ in Fig. 1(a). In the case of the $\mathrm{Cd}-\mathrm{Zn}$ mixture, however, the concentration pattern in Fig. 1(c) applies rather than the profile in Fig. 1(a), since both $\mathrm{Cd}$ and $\mathrm{Zn}$ are less strongly bound to the biosorbent than $\mathrm{Ca}$. Consequently, $\mathrm{Zn}$ does not overshoot when it is present in the feed with $\mathrm{Cd}$ but does overshoot in case of the $\mathrm{Cu}-\mathrm{Zn}$ feed.

The agreement between the experimental data and the model predictions in Fig. 2(a)-(d) should be considered to be only semi-quantitative since the ECM assumes a negligible mass transfer resistance, a premise which is never true in real sorption columns. As a result of this assumption, the model

\begin{tabular}{lcccc} 
Table 1. Ion exchange equilibrium constants of metals for \\
Sargassum biomass \\
\hline $\begin{array}{l}\text { Equilibrium constant } \\
\text { Value }\end{array}$ & $K_{\mathrm{CuFe}}$ & $K_{\mathrm{CaFe}}$ & $K_{\mathrm{CdFe}}$ & $K_{\mathrm{ZnFe}}$ \\
& 6.700 & 3.333 & 2.258 & 1.508
\end{tabular}


breakthroughs in Fig. 2(a)-(d) are generally steeper than the experimental breakthroughs. However, regardless of the model limitations, the ECM yields important information from the process feasibility stand-point by providing (1) the time intervals between the breakthroughs of the individual components, and (2) the magnitude of the overshoots (where applicable). According to both the experimental and the model curves in Fig. 2(a) through (c), the breakthrough points of the low-affinity metals move along the horizontal time axis closer to the breakthrough point of $\mathrm{Cu}$ in the following order; Cd closer than $\mathrm{Zn}$ closer than Fe. This sequence corresponds to the sequence of decreasing affinity of these metals towards the biosorbent. The predictions concerning the magnitude of the overshoots of $\mathrm{Cd}, \mathrm{Zn}$ and $\mathrm{Fe}$ are also in a reasonable agreement with the experimental data. Although, due to slow mass transfer, $\mathrm{Cu}$ in Fig. 2(c) broke through the column before $\mathrm{Cd}$ could reach the level of the maximum overshoot predicted by the ECM.

\section{Assessment of overshoots in a Cu biosorption process}

Ternary systems classified as A,C exchanging on B-resin, were further analyzed by means of the
ECM. Specifically, the effect of the overshoot of $\mathrm{C}$ on the efficiency of removal of $\mathrm{A}$ in a column was investigated for the case of $\mathrm{A}=\mathrm{Cu}$ and $\mathrm{B}=\mathrm{Ca}$. Figure 3 summarizes the results of the ECM simulations in the form of two curves showing the dependence of the maximum overshoot of $\mathrm{C}$ and the time interval $\mathrm{T}_{23}{ }^{\prime}-\mathrm{T}_{12}$, respectively, on the value of the equilibrium constant $K_{\mathrm{AC}}$. Based on the curves in Fig. 3, three different categories of species $\mathrm{C}$ may be recognized. Species $\mathrm{C}$ from the first category have their affinities towards the biosorbent just slightly lower than the affinity of $\mathrm{B}$, i.e. when $K_{\mathrm{AB}} \cong K_{\mathrm{AC}} \quad\left(K_{\mathrm{AC}}\right.$ in Fig. 3 approaching 2.3). Although high overshoots are predicted to happen for such species, these overshoots bear only a limited significance for the process feasibility because they occur in relative proximity of the breakthrough of the targeted species A. For the specific case of Sargassum biosorbent in the Ca-form and water rich in $\mathrm{Cu}$, Fig. 2(c) demonstrates that $\mathrm{Cd}$ may be an example of a species from the first group. The second group is formed by species $\mathrm{C}$ whose affinity is an order of magnitude lower than the affinity of A, i.e. $K_{\mathrm{AC}}>10$. The overshoots of these species are negligible and hence do not pose any problem
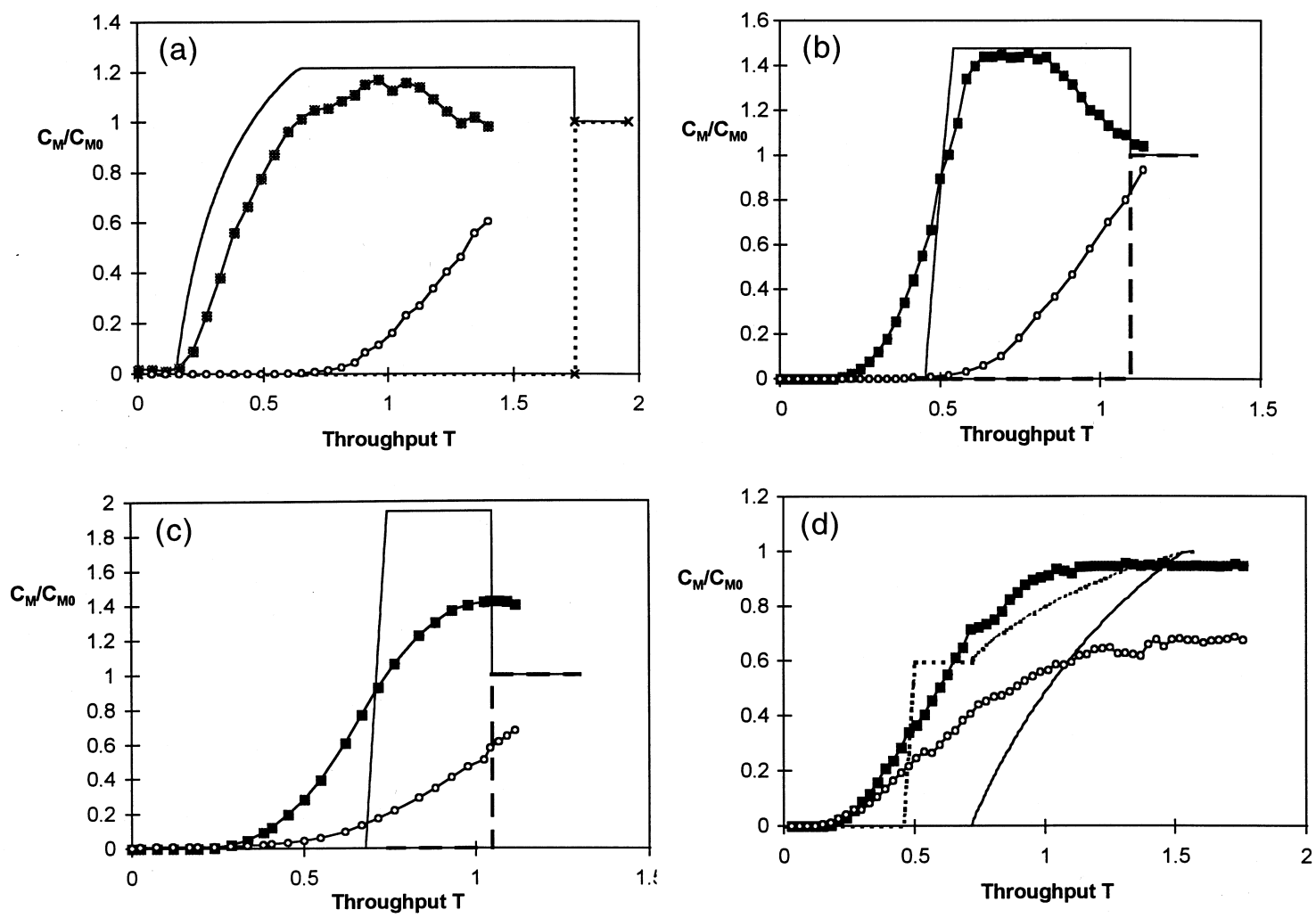

Fig. 2. Comparison of experimental and model breakthroughs for Ca-Sargassum and feed containing: (a) $120 \mathrm{mg} / \mathrm{l} \mathrm{Cu}^{2+}, 110 \mathrm{mg} / \mathrm{F} \mathrm{Fe}^{2+}:(\bigcirc) \mathrm{Cu}$ experiment; ( $\square$ ) Fe experiment; $(\bullet \bullet) \mathrm{Cu}$ model; $(\longrightarrow) \mathrm{Fe}$ model. (b) $30 \mathrm{mg} / 1 \mathrm{Cu}^{2+}, 4 \mathrm{mg} / 1 \mathrm{Zn}^{2+}$ : (O) Cu experiment; ( $\square$ ) $\mathrm{Zn}$ experiment; (- ) Cu model; (一) $\mathrm{Zn}$ model. (c) $30 \mathrm{mg} / 1 \mathrm{Cu}^{2+}, 4 \mathrm{mg} / 1 \mathrm{Cd}^{2+}$ : (O) Cu experiment; (ם) Cd experiment; (- -) Cu model;

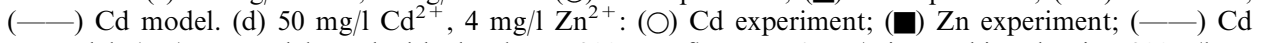
model; $(\bullet \bullet) \mathrm{Zn}$ model. Packed bed volume: $200 \mathrm{~mL}$; flowrate: $3 \mathrm{~cm} / \mathrm{min}$; packing density: $200 \mathrm{~g} / \mathrm{l}$. 


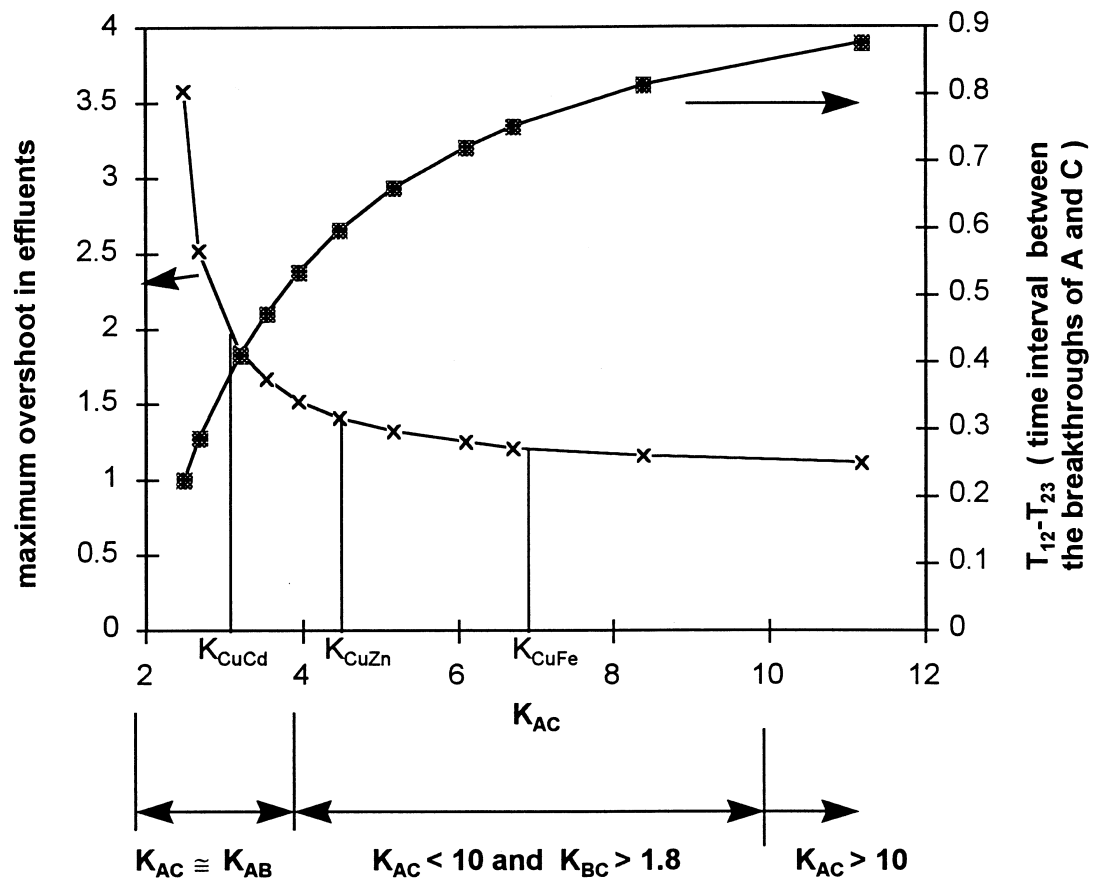

Fig. 3. Analysis of overshoots for columns packed with B-sorbent, receiving $\mathrm{A}$ and $\mathrm{C}$ in the feed. $\mathrm{A}=\mathrm{Cu} ; \mathrm{B}=\mathrm{Ca}$. ( $\square$ ) maximum overshoots predicted by the ECM; (x) distance between the breakthrough points of $\mathrm{A}$ and $\mathrm{C}$.

for an efficient removal of A in columns. Finally, the third group is represented by metal ions possessing "intermediate" affinities as compared to affinities of $\mathrm{A}$ and $\mathrm{B}$, yielding $K_{\mathrm{BC}}>2$ and $K_{\mathrm{AC}}<10$. It is the metals from this third group that have the potential to drastically reduce the efficiency of the biosorption of A. For the specific case of Sargassum biosorbent in the $\mathrm{Ca}$-form and wastewater rich in $\mathrm{Cu}$, the metal species which qualify as members of this group are $\mathrm{Fe}$, and $\mathrm{Zn}$. However, since $\mathrm{Fe}$ is not considered toxic, $\mathrm{Zn}$ is the only metal which may, due to its overshooting, render the removal of $\mathrm{Cu}$ by Sargassum bisorbent in columns inefficient. Although in the present work $\mathrm{A}=\mathrm{Cu}$ and $\mathrm{B}=\mathrm{Ca}$, the conclusions drawn from the results displayed in Fig. 3 may be easily generalized to apply to any detoxification process which uses a biosorbent in the B-form to treat wastewater containing a relatively high level of metal A in combination with low levels of metal $\mathrm{C}$.

Combining ECM and MTCM to determine the column service time in multi-metal mixtures

In addition to the ability to predict the existence and the extent of the overshoots, the ECM can also be used to (1) determine the elution order of the sorbed metals, and (2) reduce the number of species to be specified in the MTCM.

One of the essential characteristics of the ECM is that, based on the series (6), the elution order pre-


Fig. 4. Effluent concentration history predicted by the ECM. (---) Ca; (-) Zn; (--) Cd; (-) Cu. (b) Effluent concentration history determined experimentally (x) Ca; (

$\mathrm{Zn}$; (o) Cd; (-) Cu. Packed bed volume: $200 \mathrm{~mL}$; flowrate: $3 \mathrm{~cm} / \mathrm{min}$; packing density: $200 \mathrm{~g} / \mathrm{l}$. 




Fig. 5. Comparison of $\mathrm{Zn}$ breakthroughs from 4-component and 2-component systems. ( $\square$ ) Zn breakthrough from $\mathrm{Cu}-\mathrm{Cd}-\mathrm{Zn}-\mathrm{Ca}$ system; Feed Cu-Cd-Zn 1-1-1 mmol/1; (o) Zn breakthrough from Ca-Zn system; Feed Ca-Zn 2-1 mmol/1.

dicted by the model always follows the affinity sequence of the components towards the biosorbent. Consequently, regardless of the composition of the feed, the ECM predicts that the species with the lowest affinity always breaks through the column first, followed by the other components from the feed in the order of increasing affinity.

The principles behind the reduction of the number of species are those of the "key" component and of the "last" transition. The key component in the wastewater is the toxic species whose concentration in the column effluent first exceeds the discharge limit set by regulations, thereby determining the service time of the column and hence also the biomass usage rate in the process. The ultimate goal of all existing MTCMs is to provide a good estimate for the breakthrough point of the key component. However, a knowledge of N-1 mass transfer coefficients is necessary in order to run dynamic column simulations of $\mathrm{N}$-component systems. These coefficients are very often unknown as they depend on a variety of factors. The most important of factors include the physical properties and the chemical composition of the sorbent, and the character of metal-sorbent interactions.

Using the ECM approach of plateaus and transitions, the breakthrough of the key component can be viewed as a mirror image of the "last" transition in the column, provided that the species with the lowest affinity in the system is toxic. As mentioned above, the number of species present in any given transition is lower the farther from the feed side of the column the transition develops. Consequently, the last transition contains the least number of components of all the transitions in the column. The ECM then reduces the amount of information needed for the MTCM by specifying which components are present in the last transition.

In order to test whether this feature of the ECM is applicable to biosorption, the following simulations and experiments were conducted. First, a model profile was calculated for feed containing an equimolar mixture of $\mathrm{Cu}, \mathrm{Cd}$ and $\mathrm{Zn}$, i.e. $x_{\mathrm{Cu}}=x_{\mathrm{Cd}}=x_{\mathrm{Zn}}=0.33$, and $1 \mathrm{mmol} / 1$ each. The result of this calculation is shown in Fig. 4(a). According to the model, and in an agreement with the values of the equilibrium constants from Table 1, Zn breaks through the column first, followed by $\mathrm{Cd}$ and finally by $\mathrm{Cu}$. Consequently, the ECM identified $\mathrm{Zn}$ as the "key" component and $\mathrm{Ca}$ and $\mathrm{Zn}$ as the only species present in the last transition. The model further predicted that both $\mathrm{Zn}$ and $\mathrm{Cd}$ would overshoot in the column effluent and that the magnitude of the $\mathrm{Cd}$ overshoot is higher than that of $\mathrm{Zn}$. Finally, according to the model, the time interval between the breakthroughs of $\mathrm{Zn}$ and $\mathrm{Cd}$ is much shorter than the distance between the breakthrough points of $\mathrm{Cd}$ and $\mathrm{Cu}$. Next, a column experiment was performed and the experimental breakthrough curves were plotted in Fig. 4(b). By comparing Fig. 4(a) and (b) it can be concluded that the experiment confirmed all of the model predictions mentioned above.

Due to the stoichiometry of the ion exchange, the removal of the strongly binding ions of $\mathrm{Cu}$ and $\mathrm{Cd}$ in the upper parts of the column results in the 


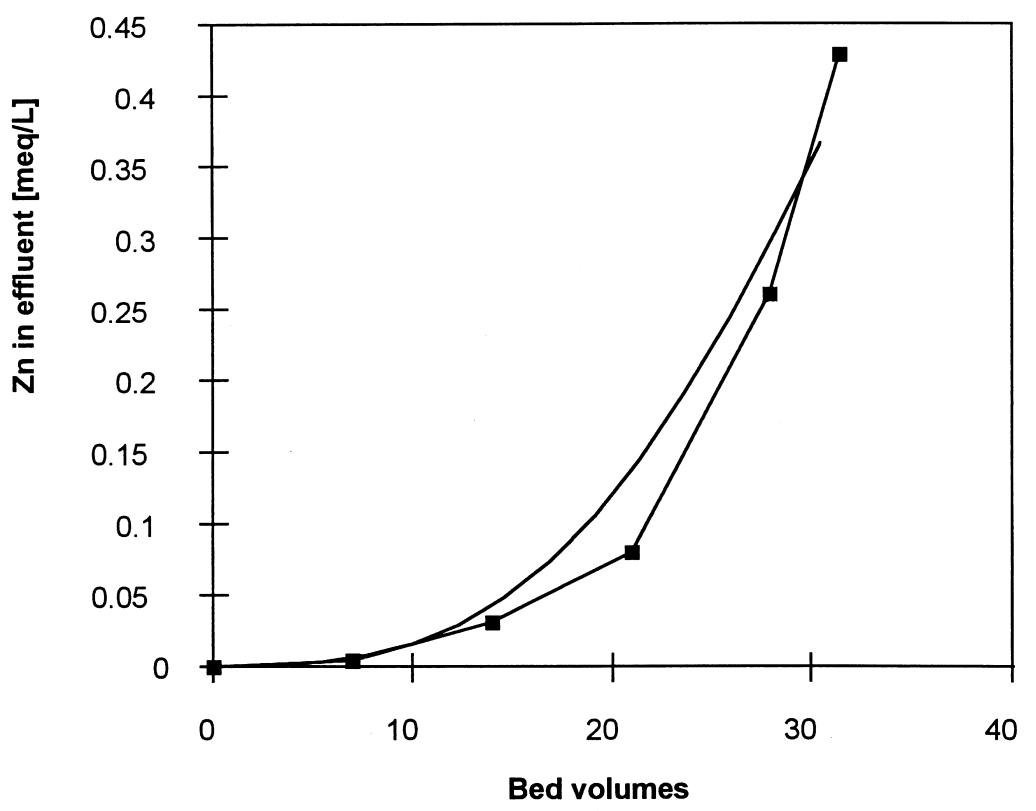

Fig. 6. Predicting the service time of a column treating multicomponent mixtures by means of MTM for binary ion exchange systems. ( $\square)$ experimental breakthrough of $\mathrm{Zn}$ from $(\mathrm{Cu}-\mathrm{Cd}-\mathrm{Zn}-\mathrm{Ca})$ system; (- ) MTCM prediction of Zn breakthrough for binary system (Ca-Zn).

release of an equivalent amount of $\mathrm{Ca}$ ions. These $\mathrm{Ca}$ ions are then carried down stream where they effectively interfere in the sorption of weakly binding $\mathrm{Zn}$. Provided that the removal of $\mathrm{Cu}$ and $\mathrm{Cd}$ ions in the upper part of the column is complete and that no significant amount of $\mathrm{Zn}$ is removed simultaneously with $\mathrm{Cu}$ and $\mathrm{Cd}$, the liquid entering the lower part of the column contains $\mathrm{Zn}$ at the feed level and $\mathrm{Ca}$ at a level corresponding to the sum of the feed concentrations of $\mathrm{Cu}$ and $\mathrm{Cd}$. The last column experiment was then carried out with the feed containing $2 \mathrm{mmol} / \mathrm{l}$ of $\mathrm{Ca}$ and $1 \mathrm{mmol} / \mathrm{l}$ of $\mathrm{Zn}$. As can be seen from Fig. 5, the breakthrough points of $\mathrm{Zn}$ from the $(\mathrm{Ca}-\mathrm{Zn})$ feed and from the $(\mathrm{Cu}-\mathrm{Cd}-\mathrm{Zn})$ feed (from Fig. 4(b)) coincide. This implies that, for the biosorption system $(\mathrm{Cu}-\mathrm{Cd}-$ $\mathrm{Zn}-\mathrm{Ca}$ ), the application of the concepts of the "key component" and of the "last transition" may successfully reduce the number of components from four to two. Subsequently, for the purpose of esti- mating the service time of a column, the system was modeled as a binary system $(\mathrm{Ca}-\mathrm{Zn})$ using the MTCM previously introduced by Kratochvil et al. (1997). The early stage of the resulting model breakthrough curve of $\mathrm{Zn}$ is compared in Fig. 6 to the corresponding stage of the breakthrough obtained experimentally from the four-component system $(\mathrm{Cu}-\mathrm{Cd}-\mathrm{Zn}-\mathrm{Ca})$. The value of the overall mass transfer coefficient of $0.0154 \mathrm{~min}^{-1}$ was determined by fitting the MTCM to the experimental breakthrough curve.

Table 2 summarizes information about a biosorption process which employs Sargassum biomass in the Ca-form to treat four different types of wastewater. While most of the results presented in Table 2 have already been discussed at length in the previous section, two conclusions shown in Table 2 deserve a special comment. First, the finding of "no overshoots" during the operation of a column treating wastewater I containing mainly $\mathrm{Zn}$ in combi-

Table 2. Evaluation of a biosorption process to treat heavy metal pollution - summary

\begin{tabular}{|c|c|c|c|c|c|c|}
\hline \multirow[t]{2}{*}{ Wastewater } & \multicolumn{2}{|c|}{ Composition } & \multicolumn{2}{|r|}{ Overshoots } & \multirow[t]{2}{*}{ Key component } & \multirow[t]{2}{*}{ Species to be specified in the MTM model } \\
\hline & Metal & Level & Species & Risk of treatment efficiency reduction & & \\
\hline I & $\begin{array}{c}\mathrm{Zn} \\
\mathrm{Cd}, \mathrm{Cu}\end{array}$ & $\begin{array}{l}\text { High } \\
\text { Low }\end{array}$ & None & None & $\mathrm{Zn}$ & $\mathrm{Zn}, \mathrm{Ca}$ \\
\hline II & $\begin{array}{c}\mathrm{Cu} \\
\mathrm{Cd}, \mathrm{Fe}\end{array}$ & $\begin{array}{l}\text { High } \\
\text { Low }\end{array}$ & $\mathrm{Cd}, \mathrm{Fe}$ & Low & $\mathrm{Cu}$ & $\mathrm{Cu}, \mathrm{Cd}, \mathrm{Ca}$ \\
\hline III & $\begin{array}{c}\mathrm{Cu} \\
\mathrm{Zn}, \mathrm{Fe}\end{array}$ & $\begin{array}{l}\text { High } \\
\text { Low }\end{array}$ & $\mathrm{Zn}, \mathrm{Fe}$ & High & $\mathrm{Zn}$ & $\mathrm{Zn}, \mathrm{Ca}$ \\
\hline IV & $\begin{array}{l}\mathrm{Cu} \\
\mathrm{Zn} \\
\mathrm{Cd}\end{array}$ & $\begin{array}{l}\text { High } \\
\text { High } \\
\text { High }\end{array}$ & $\mathrm{Zn}, \mathrm{Cd}$ & High & $\mathrm{Zn}$ & $\mathrm{Zn}, \mathrm{Ca}$ \\
\hline
\end{tabular}


nation with low amounts of $\mathrm{Cu}$ and/or $\mathrm{Cd}$ is caused by the fact that both $\mathrm{Cd}$ and $\mathrm{Cu}$ have higher affinities towards Sargassum than $\mathrm{Zn}$. Thus $\mathrm{Cu}$ and $\mathrm{Cd}$ break through the column after $\mathrm{Zn}$ which is both the targeted metal and the key component. Also deserving a comment is the conclusion identifying $\mathrm{Cu}$ as the key component for wastewater II in Table 2. This conclusion follows from Fig. 2(c) which shows that the breakthrough of $\mathrm{Cu}$ precedes the overshoot of $\mathrm{Cd}$, hence the column service time for this wastewater is limited by the breakthrough point of $\mathrm{Cu}$. Since in this case the key component is not the one with the lowest affinity in the system, all species in the system, i.e. $\mathrm{Cu}, \mathrm{Cd}, \mathrm{Ca}$ and $\mathrm{Fe}$, must be specified in the MTCM.

Although the reduction in the number of species that must be specified in the MTCM may not be always possible, tables similar to Table 2 may easily be constructed by using the ECM for other biosorbents and/or a broader spectrum of toxic heavy metals.

\section{REFERENCES}

Al-Asheh S. and Duvniak Z. (1995) Adsorption of copper and chromium by Aspergillus carbonarius. Biotechnol. Prog. 11, 638-642.

Churchill S. A., Walters J. V. and Churchill P. F. (1995) Sorption of heavy metals by prepared bacterial cell surfaces. J. Environ. Eng. 121, 706-711.

Costa A. C. A., Mesquita L. M. S. and Tosovsky J. (1996) Batch and continuous heavy metal biosorption by brown seaweed from a zinc-producing plant. Minerals Engineering 9, 811-824.

Crist R. H., Martin J. R., Carr D., Watson J. R., Clarke H. J. and Crist D. R. (1994) Interaction of metals and protons with algae - 4. Ion exchange vs adsorption models and a reassessment of Scatchard plots; ionexchange rates and equilibria compared with calcium alginate. Environ. Sci. Technol. 28, 1859-1866.

deVault D. (1943) The theory of chromatography. $J$. Amer. Chem. Soc. 65, 532-540.

Fletcher C. A. J. (1984) Computational Galerkin Methods. Springer-Verlag, New York, pp. 246-276.
Fourest E. and Roux J.-C. (1994) Improvement of heavy metal biosorption by mycelial dead biomass (Rhizopus arrhizus, Mucor miehei and Penicillium chrysogenum): $\mathrm{pH}$ control and cationic activation. FEMS Microbiol. Rev. 14, 325-332.

Helfferich F. G. (1967) Multicomponent ion exchange in fixed beds. Ind. Eng. Chem. Fundam. 6, 362-364.

Hiester N. K. and Vermeulen H. (1952) Saturation performance of ion-exchange and adsorption columns. Chem. Engng. Prog. 48, 505-516.

Jansson-Charrier M., Guibal E., Roussy J., Surjous R. and LeCloirec P. (1996) Dynamic removal of uranium by chitosan: influence of operating parameters. Wat. Sci. Tech. 34, 169-177.

Klein G., Tondeur D. and Vermeulen T. (1967) Multicomponent ion-exchange in fixed beds. Ind. Eng. Chem. Fundam. 6, 339-350.

Kratochvil D. and Volesky B. (1997) Biosorption process for removal of $\mathrm{Cu}$ from ferruginous wastewater. Water Res. 32, 2760-2768.

Kratochvil D., Volesky B. and Demopoulos G. (1997) Optimizing $\mathrm{Cu}$ removal/recovery in a biosorption column. Wat. Res. 31, 2327-2339.

Muraleedharan T. R., Philip L., Iyengar L. and Venkobachar C. (1994) Application studies of biosorption for monazite processing industry effluents. Biores. Technol. 49, 179-186.

Schiewer S. and Volesky B. (1996) Modeling of multimetal ion exchange in biosorption. Environ. Sci. Tech nol. 30, 2921-2927.

Tan H. K. S. and Spinner I. H. (1994) Multicomponent ion exchange dynamics. Can J. Chem. Eng. 72, 330-341.

Tondeur D. and Klein G. (1967) Multicomponent ion exchange in fixed beds. Ind. Eng. Chem. Fundam. 6, 351-361.

Trujillo E. M., Jeffers T. H., Ferguson C. and Stevenson H. Q. (1991) Mathematically modeling the removal of heavy metals from wastewater using immobilized biomass. Environ. Sci. Technol. 25, 1559-1565.

Tsezos M., Remoudaki E. and Angelatou G. (1995) A systematic study on equilibrium and kinetics of biosorptive accumulation. Internat. Biodeter. Biodegrad. 1995, 129 153.

Vermeulen T., Klein G. and Heister N. K. (1973) Adsorption and ion exchange. In Chemical Engineers' Handbook, 5th ed., eds R. H. Perry and C. H. Chilton. McGraw-Hill, NY chap. 16.

Volesky B. and Prasetyo I. (1994) Cadmium removal in a biosorption column. Biotechnol. Bioeng. 43, 1010-1015. 